Design of a High Field Stress, Velvet Cathode for the Flash X-Ray (FXR) Induction Accelerator

T.L. Houck, C.G. Brown, D.E. Fleming, B.R. Kreitzer, K.E. Lewis, M.M. Ong, J.M. Zentler

June 12, 2007

2007 Particle Accelerator Conference Albuquerque, NM, United States June 25, 2007 through June 29, 2007 
This document was prepared as an account of work sponsored by an agency of the United States Government. Neither the United States Government nor the University of California nor any of their employees, makes any warranty, express or implied, or assumes any legal liability or responsibility for the accuracy, completeness, or usefulness of any information, apparatus, product, or process disclosed, or represents that its use would not infringe privately owned rights. Reference herein to any specific commercial product, process, or service by trade name, trademark, manufacturer, or otherwise, does not necessarily constitute or imply its endorsement, recommendation, or favoring by the United States Government or the University of California. The views and opinions of authors expressed herein do not necessarily state or reflect those of the United States Government or the University of California, and shall not be used for advertising or product endorsement purposes. 


\title{
DESIGN OF A HIGH FIELD STRESS, VELVET CATHODE FOR THE FLASH X-RAY (FXR) INDUCTION ACCELERATOR *
}

\author{
T. Houck, C. Brown, D. Fleming, B. Kreitzer, K. Lewis, M. Ong, and J. Zentler \\ Lawrence Livermore National Laboratory, Livermore, CA 94550, U.S.A.
}

\begin{abstract}
A new cathode design has been proposed for the Flash X-Ray (FXR) induction linear accelerator with the goal of lowering the beam emittance. The original design uses a conventional Pierce geometry and applies a peak field of $134 \mathrm{kV} / \mathrm{cm}$ (no beam) to the velvet emission surface. Voltage/current measurements indicate that the velvet begins emitting near this peak field value and images of the cathode show a very non-uniform distribution of plasma light. The new design has a flat cathode/shroud profile that allows for a peak field stress of $230 \mathrm{kV} / \mathrm{cm}$ on the velvet. The emission area is reduced by about a factor of four to generate the same total current due to the greater field stress. The relatively fast acceleration of the beam, approximately $2.5 \mathrm{MeV}$ in $10 \mathrm{~cm}$, reduces space charge forces that tend to hollow the beam for a flat, nonPierce geometry. The higher field stress achieved with the same rise time is expected to lead to an earlier and more uniform plasma formation over the velvet surface. Simulations and initial testing are presented.
\end{abstract}

\section{INTRODUCTION}

The original diode design has been in use 11 years. Motivation to change the diode has occurred in recent years as improvements in the pulsed power, damping of higher order modes in the accelerating cells, and upgrades to transport magnets placed emphasis on improving the beam emittance to decrease the radiographic spot size. Emittance measurements indicate that FXR is a factor of four higher than similar accelerators and the injector is considered the most likely source of the high emittance [1]. Simulations performed in Reference [1] do not show a problem with the optical design leaving only the performance of the velvet emitter in question. The original design has a relatively low electric field stress and emission begins late in the applied voltage pulse.

\section{DESIGN}

Many factors need to be considered in a diode redesign. A major constraint is that FXR is an operational, user facility. Changes need to be completed during relatively short maintenance periods and the injector must be reconfigurable to its original condition. This constraint prevents changes to the anode and to the cathode stalk. Transport magnet locations are also fixed. However, diode voltage is flexible. In recent years, the injector has been operated at $2.1 \mathrm{MV}$, but it was originally designed

\footnotetext{
* This work was performed under the auspices of the U.S. Department of Energy by University of California, Lawrence Livermore National Laboratory under Contract W-7405-Eng-48.
}

for $2.5 \mathrm{MV}$. The nominal current is $3.3 \mathrm{kA}$, but values between $3-3.3 \mathrm{kA}$ are deemed sufficient if the final beam energy is increased to maintain radiation dose. In addition, a number of minor mechanical issues related to alignment, current joints, etc. had been identified. The pulse width needs to match the accelerator's pulse width. Design parameters for the new cathode are provided in Table 1 and discussed below.

Table 1: Design parameters for original/new cathodes.

\begin{tabular}{|l|c|c|}
\hline \multicolumn{1}{|c|}{ Parameter } & Original & New \\
\hline Emitter Diameter (cm) & 10.8 & 5.7 \\
\hline Emitter Field (kV/cm) & 134 & 230 \\
\hline Cathode Shroud Field (kV/cm) & 250 max & 280 max \\
\hline Diode Voltage (MV) & 2.1 & 2.5 \\
\hline Emitted Current (kA) & 3.3 & 3.2 \\
\hline Pulse Width (ns) & 67 & 67 \\
\hline Emittance (norm. edge cm-mr) & $\begin{array}{c}320 \\
\text { measured }\end{array}$ & $\begin{array}{c}108 \\
\text { design }\end{array}$ \\
\hline
\end{tabular}

\section{Electrostatic and Orbit Modeling}

The TriComp [2] suite of FE codes was used for the time independent modeling. Electrostatic modeling was used to determine the general shape of the cathode shroud and its position with respect to the anode. The shroud is aluminum with a hard anodized finish. Past operations with this type of surface finish indicated that surface fields up to $300 \mathrm{kV} / \mathrm{cm}$ are acceptable. A high emitter field stress was desired based on published results [3] indicating a lower emittance with increased field stress.

Orbit modeling was used to establish the emitter diameter to produce the desired current and determine the magnetic transport fields. Figure 1 shows orbits superimposed on electrical field contours for the first meter of transport. Simulations were performed for the four meters from the cathode to the exit of the injector including the magnetic fields of the ten injector solenoids and the first two solenoids after the injector. The injector has six induction cells on the cathode side and four cells around the anode stalk. The emittance calculated in the simulations is comparable to similar accelerators.

The magnetic transport field is energy sensitive allowing approximately a $\pm 5 \%$ variation in energy to be transported without current loss. This arrangement removes the lower energy rise and fall of the beam pulse.

\section{LSP Time Dependent Modeling}

A major pulsed power concern is the width of the beam pulse exiting the injector. The "flat top" portion of the 
accelerator cell voltage pulse can accept up to $67 \mathrm{~ns}$ of beam pulse. A longer pulse would overlap the rise and/or fall of the accelerating pulse leading to an unacceptable energy variation. The higher field stress design leads to emission beginning earlier in the injector voltage pulse. This means that the current from the cathode more closely matches the applied voltage pulse and will have greater

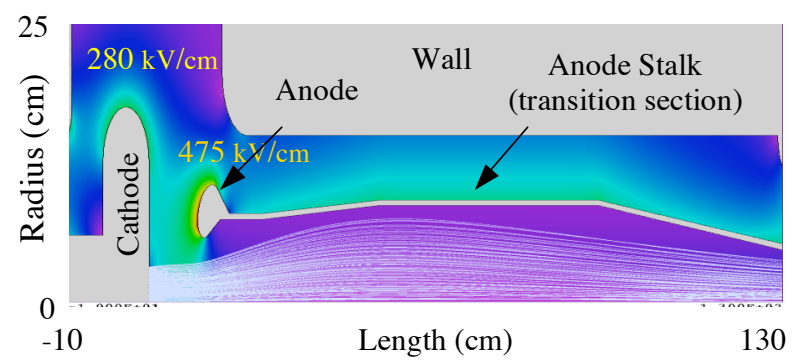

Figure 1: Simulation of emission and electric field for new cathode. Field values shown are maximum values for the cathode and anode.

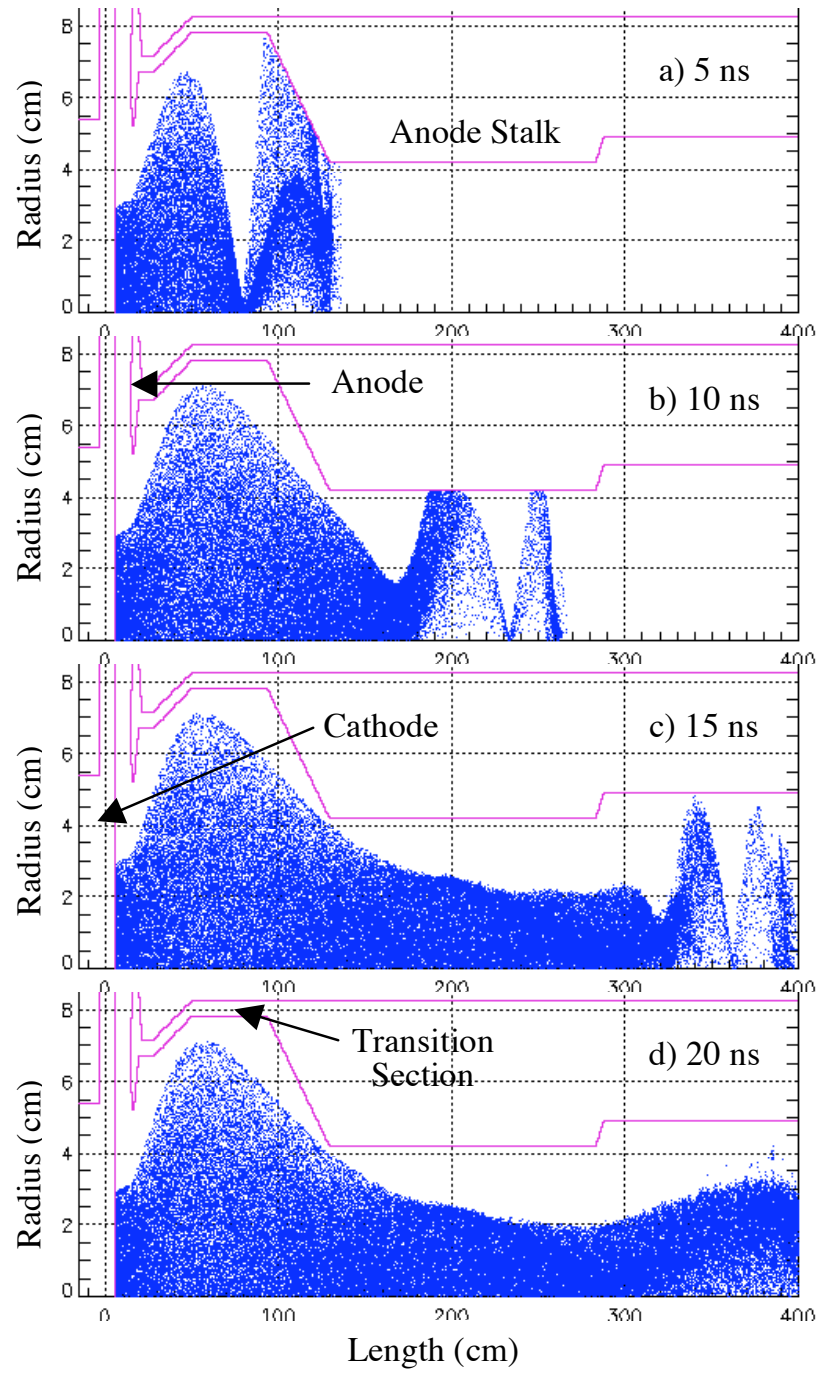

Figure 2: Snap shots in time as head of beam passes through the injector in $5 \mathrm{~ns}$ steps. Note that the vertical and horizontal scales are different. width than with the original design. LSP [4] was used to study the scraping of the head and tail of the pulse. Note that the injector has a long transition section that acts as an energy selector. Figure 2 is a series of simulation snapshots of the beam every 5 ns after voltage is applied to the diode. For the simulation, space charge limited emission began once the field stress reached $25 \mathrm{kV} / \mathrm{cm}$ on the emission surface. The voltage is ramped to $2.5 \mathrm{MV}$ so as to produce a $5-95 \%$ rise of $5.5 \mathrm{~ns}$ at the diode. In Figure $2 \mathrm{a}$ the diode voltage is reaching the "flat top" value of $2.5 \mathrm{MV}$. Thus, electrons already in the simulation will reach an energy less than the design value of $2.5 \mathrm{MeV}$. By Figure $2 \mathrm{~d}$ the simulation has reached a steady state. The early emission electrons, or head of the beam, are initially over focused then rapidly expand intercepting the wall. Figure 3 shows the current at $50 \mathrm{~cm}$ (before scraping) and at $300 \mathrm{~cm}$ after the cathode to illustrate the rise-time sharpening effect of the transition section. Although the emitted pulse is wider in the new design, the expectation is that the width of the current pulse exiting the injector will be similar for both designs.

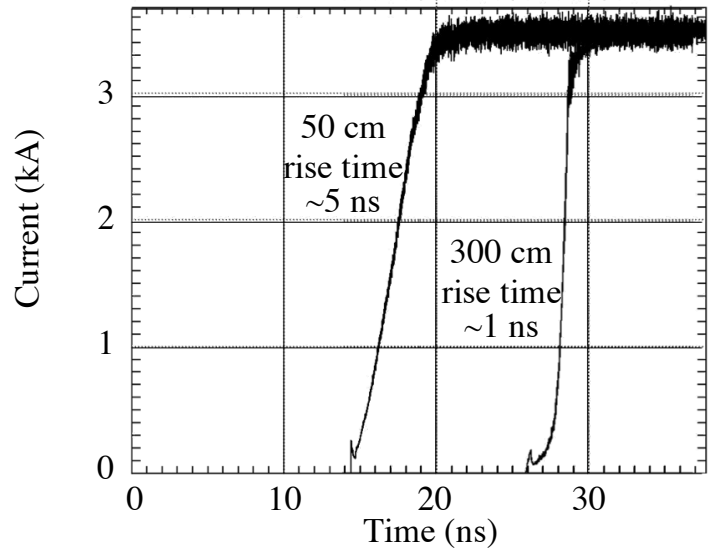

Figure 3: Current as a function of time at $50 \mathrm{~cm}$ and at $300 \mathrm{~cm}$ to illustrate the rise time sharpening of the pulse.

\section{INITIAL TESTING}

The new cathode was installed and pulsed during a two-week scheduled maintenance window. The new cathode is shown in Figure 4. The pumping spool around the diode region was slid forward over the transition section for an obstructed view of the cathode and anode.

\section{Cathode Images}

A gated, intensified camera was used to take images of the velvet emitter and cathode shroud. Figure 5 is a false color image of the plasma light observed approximately $30 \mathrm{~ns}$ after the start of emission for the two cathodes. The camera was gated for a $10 \mathrm{~ns}$ pulse. Due to the mechanical location of ports with respect to the cathode, the viewing angle is about 75 degrees with respect to the normal leading to the foreshortened image. Figure 5 has been cropped for a better view of the velvet emitting area. The total field of view included the near edge of the shroud. Images were taken over a time span of $650 \mathrm{~ns}$ to check for late time plasma formation. No light other than 
from the velvet emission area was noted for the new design. The intensity of the light is about twice as great at the periphery than at the center for both cathodes. However, the light intensity is more uniform, i.e. has fewer and less intense "hot" spots, for the new design.

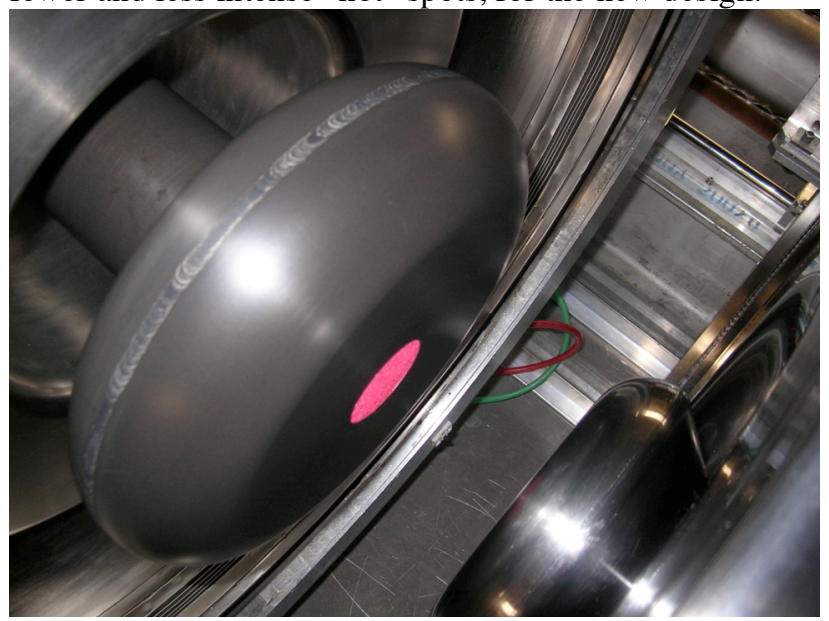

Figure 4: Photograph of the new cathode. The emitter surface is the red velvet at the center.

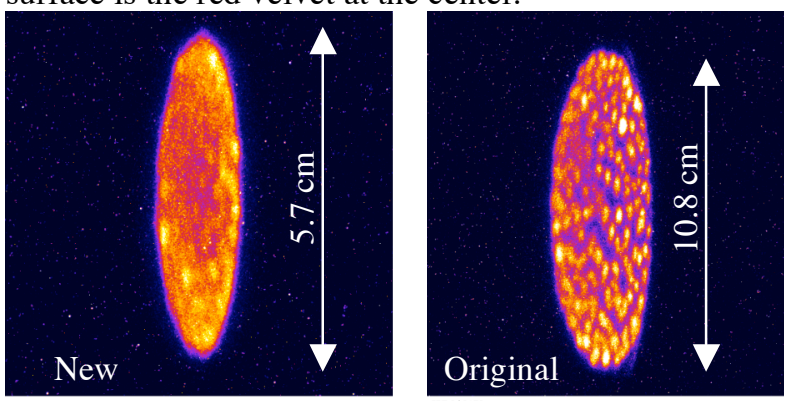

Figure 5: $10 \mathrm{~ns}$ gated image of velvet approximately $30 \mathrm{~ns}$ after the start of emission for the new and original cathodes. Note the different scales.

\section{Current Traces}

The current as a function of time is displayed in Figures 6 and 7. Figure 6 is the current measured at the diode prior to any wall loses. Both original and new cathode traces are shown to emphasize the earlier emission with the new configuration. The pronounced current overshoot and lack of "flat top" is due to a mismatch of the pulsed power. Figure 7 is the current measured at the injector exit. An original trace is shown to emphasize the similarities in rise time after wall losses. The transport magnetic fields were adjusted for the higher energy range of the pulse. This resulted in the premature clipping of the back of the pulse and a smaller pulse width. Before operations, the pulsed power will be adjusted and the pulse exiting the injector should have a similar width as the original design.

\section{SUMMARY AND PLANS}

A new cathode has been installed in the FXR injector. Initial measurements indicate the proper perveance and no shroud emission. Images of the plasma light from the emitting surface is noticeably more uniform than the original design. The next step will be to adjust the injector's pulsed power to produce a level "flat top" energy. The change in energy will require a retune of the accelerator. The emittance of the beam and radiographic spot size will be measured. The final figure of merit will be spot size.

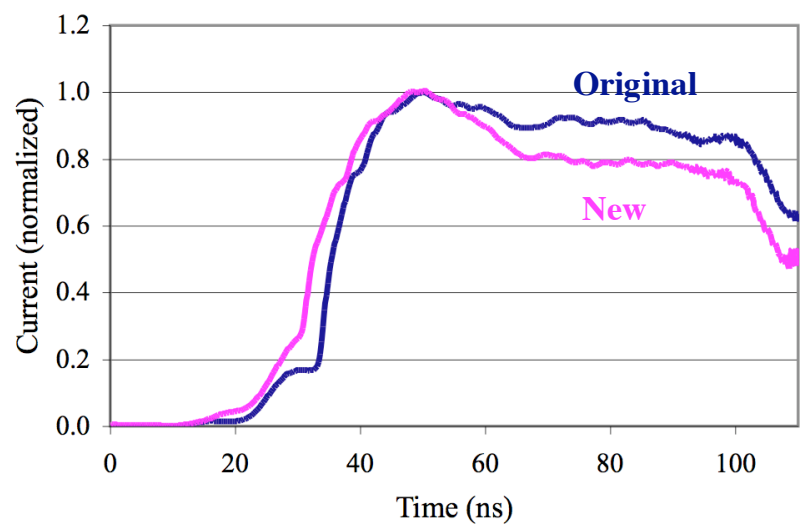

Figure 6: Emitted current measured at the diode.

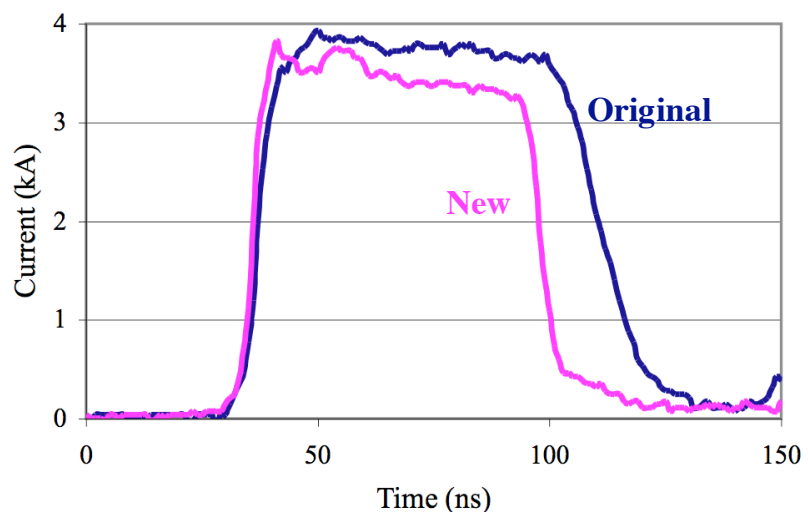

Figure 7: Current at the exit of the injector

\section{ACKNOWLEDGEMENTS}

Art Paul and Yu-Jiuan Chen of LLNL provided advice and reviewed the conceptual design. Paul Wargo, Al Traille, and Rob Buckles of National Security Technology, LLC provided camera support. Jim Dunlap was the accelerator operator during the cathode testing.

\section{REFERENCES}

[1] A. Paul, "FXR Injector and Accelerator Study," UCRL-TR-212069, LLNL, May 2005.

[2] S. Humphries, "TriComp Software Package", Field Precision, http:/www.fieldp.com, Albuquerque, NM.

[3] D.A. Shiffler, et al., "Emission Uniformity and Emittance of Explosive Field-Emission Cathodes", IEEE Trans. Plasma Sci., vol30, pp. 1592-1595, August 2002.

[4] LSP is a 3-D electromagnetic PIC code used for large-scale plasma simulations. The code is licensed by ATK Mission Systems 